\title{
Identifying, Evaluating and Prioritizing the Factors Affecting the Effectiveness of In-Service Training Courses (Case Study: English Language Teachers of the Secondary Schools in Tehran Selected Districts)
}

\author{
Zahra Alinejad $^{1}$ \\ ${ }^{1}$ University of Applied Science and Technology, Iran \\ Correspondence: Zahra Alinejad, MA in Teaching English, University of Applied Science and Technology, Iran. \\ E-mail: esfehani.mohamad3@gmail.com
}

Received: April 14, 2016 Accepted: April 30, 2016 Online Published: May 25, 2016

doi:10.5539/ijel.v6n3p221 URL: http://dx.doi.org/10.5539/ijel.v6n3p221

\begin{abstract}
The current study seeks to identify, extract, evaluate, and prioritize the factors affecting the effectiveness of in-service training course for English language teachers of the secondary schools in Tehran selected districts. The research is applied, and its data collection methodology is descriptive-survey. The statistical population is composed of all of the English language teachers $(n=230)$ practicing in Tehran districts 2 and 4 who participated at least once in one of in-service training courses. Out of all participants, 102 were selected as the sample for data collection using stratified random sampling method. The required data were collected through one standard questionnaire. Data analysis was performed using descriptive and inferential statistical methods. The prioritization of the indices was performed using multi-criteria decision-making techniques. The results from data analysis indicated that out of three factors including individual, training, and organizational, only the organizational factor had a significant positive impact on the effectiveness of in-service training of English language teachers. Hence, using TOPSIS method, the indices relevant to the organizational dimension were ranked based on the respondents' views. The results from this prioritization showed that, from the teachers' perspective, the factors with the highest priority include "employment law tailored to attend educational courses", "organizational support of educational courses", "score tailored to the course participants in terms of promotion and upgrade", and "existing a supportive organizational climate for education".
\end{abstract}

Keywords: in-service training, effectiveness, multi-criteria decision-making techniques, TOPSIS

\section{Introduction}

Failure to provide continuous and in-service training of employees leads to reduced efficiency and effectiveness and weakening of occupational identity among them. Considering that the progress of each community in all of the disciplines depends on the quality of education in that society, providing in-service educational courses for school teachers and educators is one of the most essential imperatives of educational system. When the significance of human resources is discussed, the focus is mainly shifted toward cultivated and educated people. This is because, such groups of people are sufficiently eligible and skilful to be the source of positive developments in the various sectors of society, and normally this ability and skill can be attained through training and investment in human resources sector (Pourjahromi et al., 2011, p. 898).

Most experts in the area of educational planning and management agree on the fact that the key to the balance between implementation procedures in organizations and the development and initiatives in the external environment is the use of staff in-service training as an effective mechanism (Fathivajargah, 2010, pp. 48-55).

The concept of in-service training is training during the working years, and such type of training intends to create employment opportunities, create awareness of duties and responsibilities, develop skills, the ability to upgrade to higher positions, and adapt to the new situation (Foroughi Abri et al., 2008, pp. 65-66).

In-service training, in a traditional sense and in the form of apprenticeship training, has a very long history. Today, such in-service training programs are implemented in four phases: 
1) The trainee preparation to reduce its anxiety and distress, and create interest in it.

2) Provide the trainee with the knowledge how to do the work.

3) Experimental work done by apprentices.

4) Pursue and monitor the work done by apprentices in accordance with the desired qualitative and quantitative standards (Bakhtiari \& Ahmadi, 2007, pp. 127-129).

Regarding the fourth phase, the concept of evaluating the effectiveness of in-service training comes into play. In fact, assessing the effectiveness of training courses means the determination to specify the extent of the promotion in trainees' knowledge and skill through the provided trainings (Xu \& Jiang, 2010, p. 261).

Given the importance of having qualified and motivated teachers to train skilled manpower, and given the problems confronted by in-service training courses, the current article seeks to analyze the effectiveness of these courses for English language teachers, and the relevant factors are ranked on the basis of their significance from the study participants' perspective.

\subsection{Research Literature}

In their research, Abili et al. (2009) sought to identify the factors affecting the promotion of the effectiveness of training courses held in Iranian Oil Company in three dimensions including individual, organizational and educational. The results of the analysis of the collected data showed that personal factors have the most significant impact on the effectiveness of the training courses.

In another research, the researchers analyzed the importance of four factors including technology, content, instructor, and learning practices on the effectiveness of e-courses, and also the course satisfaction from the trainees' views. After analyzing the data obtained from questionnaire, the researchers came to the conclusion that all of the four indicators play key roles in the effectiveness of educational periods, and they are as below in terms of priority:

1) Leaning style quality and methods.

2) Type of technology.

3) Content of educational courses.

4) Instructor/teacher (Khorasani \& Dousti, 2011).

Mahmoudi et al. (2012) examined the opinions held by the physicians practicing in Chaharmahal \& Bakhtiari province on the effectiveness of continuous medical education courses to provide an appropriate model. The results obtained from the analysis of research data showed that retraining and continuous education courses for doctors were influential on the different parts of the questionnaire (effectiveness, possibility of change and innovation, to inform doctors of objectives and policies, increased efficiency, and employment incentives). In addition, there was a significant relationship between effectiveness and the variables namely the number of the training courses passed by the respondents, their age, and medical practice history. The researchers concluded that, in view of respondents, holding retraining and continuous education courses was effective on the efficacy, the possibility of change and innovation, to inform doctors of objectives and policies, increased efficiency, and increased employment incentives.

Chen et al. (2007) evaluated the effectiveness of teaching and the factors affecting the effectiveness of teaching in one of the Kenyan banks. The researchers therefore examined the following six factors that influence the effectiveness of training:

a) Training needs assessment,

b) The type of educational programs,

c) Flexibility of training programs,

d) Self-efficacy,

e) Community support, and

f) Transfer of knowledge.

The researchers realized that all of the six factors have a significant relationship with the effectiveness of training courses, and the flexibility of training course and type of training course had the greatest impact on the effectiveness of the training courses.

In another research, the researchers examined the effectiveness of training courses in health sector. The results 
from the data analysis of the questionnaire indicated that educational courses held have a positive impact on the trainees' performance. In addition, some factors such as the trainee's incentive, the support of senior managers and instructors, and the choice of training courses by trainees themselves had a significant positive impact on the effectiveness of the courses (Herrero et al., 2011, pp. 320-323).

Ghosh et al. (2011), in their study, evaluated the effectiveness of training courses trainees through the trainees' reaction. To this end, they identified six factors along with the relevant indices. The data analysis results showed that all factors and indices evaluated had a significant effect on the effectiveness of the training courses. Furthermore, it was indicated that the effectiveness of communications between instructor and trainees during the training period and an explanation on how to use the training learned during the work had the greatest impact on the effectiveness of the training courses (Latif, 2012, p. 214).

Latif (2012) in its study presented the factors affecting the effectiveness of the training courses in the form of a model. The results of the data collected showed that satisfaction with training courses, satisfaction with educational content, satisfaction with instructor, and transfer of learning all have positive and significant effects on effective training and learning.

After studying the literature background, in the present article, the factors affecting the effectiveness of the training courses were introduced in the form of three factors: individual, organizational and educational, the relevant indices of each of these factors were extracted from the research background.

According to the above theoretical framework, the research questions include:

-Do the individual factors have a significant impact on the effectiveness of in-service training courses for English language middle school teachers?

-Do the organizational factors have a significant impact on the effectiveness of in-service training courses for English language middle school teachers?

-Do the training factors have a significant impact on the effectiveness of in-service training courses for English language middle school teachers?

-How do English language secondary school teachers prioritize the relevant factors in terms of significance?

\section{Research Methodology}

Given the case study selected, the current research is descriptive, and here the main intention is to examine the factors influencing a phenomena from the respondents' view, and make it applicable by offering suggestions and practical solutions. Thus, in terms of objective, the current research is applied.

\subsection{Statistical Population and Sample}

The statistical population of the current research is composed of all of the English language teachers $(\mathrm{n}=230)$ practicing in Tehran districts 2 and 4 who participated at least once in one of in-service training periods.

To determine the sample size, the research questionnaire was randomly distributed between 35 of the teachers, and the final sample size was determined given the obtained standard deviation as below:

$\mathrm{N}$ is the same total size of statistical community, and $Z_{\alpha / 2}^{2}$ was considered to be 1.96 based on the statistical books. $\delta^{2}$ is the standard deviation obtained from the primary questionnaire.

$$
n=\frac{N \times Z_{\%}^{2} \times \delta^{2}}{\varepsilon^{2}(N-1)+Z_{\alpha / 2}^{2} \times \delta^{2}} \quad \Rightarrow \quad n=\frac{230 \times(1.96)^{2} \times 0.401^{2}}{0.05^{2}(229)+(1.96)^{2} \times 0.401^{2}}=119
$$

Given the standard deviation obtained, the maximum sample size estimated at the level $5 \%$ is equal to 119 persons, which after distributing 140 questionnaire, 102 questionnaires were selected as the base for performing the analyses using stratified random sampling method.

\subsection{Data Collection Tool}

The data required in the current research were collected by field- and library-based techniques. First, using a review of books, dissertations, theses, research articles, and reliable academic websites, the dimensions and indicators of the research were extracted. Using the field-based technique, the research questionnaire, with 54 questions and 7-item Likert scale was distributed and collected after the respondents replied to the relevant items. 
Table 1. The indices and factors influencing the effectiveness of training courses (Abili et al., 2009)

\begin{tabular}{|c|c|}
\hline Dimensions/Factors & Components /indicators \\
\hline 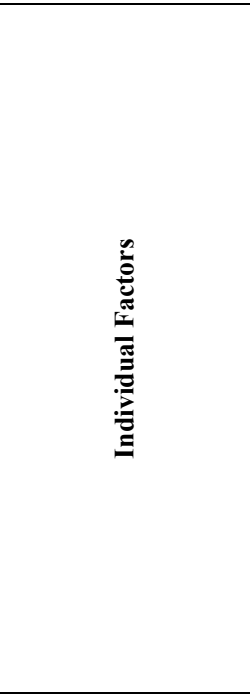 & $\begin{array}{l}\text { Target learners' personal needs during the implementation of courses } \\
\text { Motivation to attend courses } \\
\text { Considerations and conditions of the age of the participants in designing courses } \\
\text { The positive attitude of participants to attend such educational courses } \\
\text { The positive attitude of participants on their jobs and the need to improve it } \\
\text { Students' eagerness to learn new things. } \\
\text { learners' relative mastery over learning techniques and study skills } \\
\text { Consider the conditions and physical characteristics of learners in the design of the form and } \\
\text { structure of the course } \\
\text { Respect for the personality traits of students when designing the course } \\
\text { The consistency between learners' expectations and designed form and structure of the } \\
\text { courses. } \\
\text { Consider the learners' ability and individual differences } \\
\text { Learners' deep belief in the need for their continuing education } \\
\text { Learners' self-confidence tailored to their potential to learn. } \\
\text { Learners' tendency to develop their personal capabilities } \\
\text { Courses' ability to provide learners with motivation and organization } \\
\text { Learners' efforts to join and work effectively in organizations }\end{array}$ \\
\hline 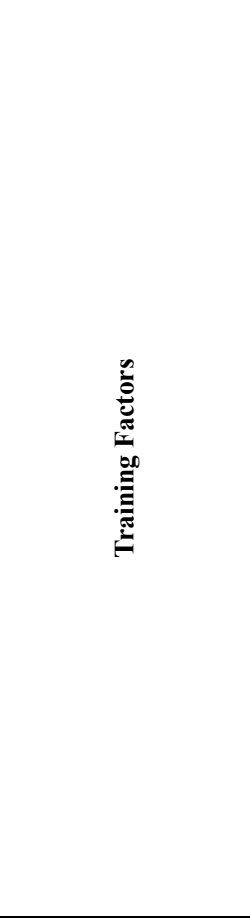 & $\begin{array}{l}\text { Duration of the course } \\
\text { Adapt content with learners' experiences } \\
\text { Updated content of the course } \\
\text { The quality of the course } \\
\text { Equipment and educational facilities of the course } \\
\text { Proper training needs assessment } \\
\text { Prioritization of educational needs } \\
\text { The course implementation form } \\
\text { Learning style and teaching methods } \\
\text { Location of form of the course implementation } \\
\text { Instructors' personal characteristics } \\
\text { Instructors' Professional mastery } \\
\text { Instructors' participation in the design of content and its presentation during the course } \\
\text { Evaluation tailored to learners' professional characteristics } \\
\text { The courses' functional content } \\
\text { Instructors' active teaching } \\
\text { The presence of common underlying theoretical and practical contexts in the course } \\
\text { Use of the learners' experience during the course } \\
\text { Possibility to transfer the learning experiences to the workplace } \\
\text { Continuous consistency between the content with learning experiences } \\
\text { Providing modern scientific achievements in the course } \\
\text { Instructors' observance of learners' psychological personality conditions } \\
\text { Consistency between the participation scheduling in the course with learners' family traits } \\
\text { Appropriate evaluation of the criteria relevant to the course }\end{array}$ \\
\hline 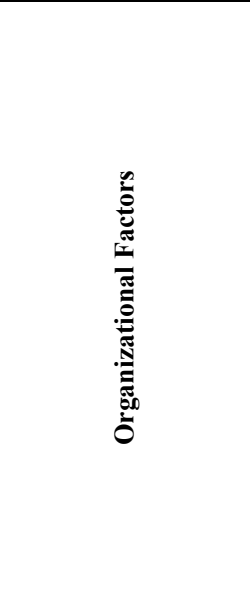 & $\begin{array}{l}\text { Organizational support of educational courses } \\
\text { Provide career counseling to participants } \\
\text { Institutional policy in line with the educational objectives } \\
\text { Organizational climate supportive of education } \\
\text { Job characteristics appropriate to the implementation of the training course } \\
\text { Employment law tailored to attend educational courses } \\
\text { The advantages and points tailored to the participants in the courses in terms of promotion } \\
\text { and upgrade } \\
\text { Allocate the leave with the least negative occupational consequences for continuing education } \\
\text { Financial supports of the course participants } \\
\text { Granting educational assistance services tailored to learners } \\
\text { The consistency between the course content and job conditions during evaluation course } \\
\text { Encouraging rules to continue to participate in future periods } \\
\text { The presence of systematic follow-up structures and to update employees' academic } \\
\text { potentials } \\
\text { Continuous assessment to update the title and content of educational courses }\end{array}$ \\
\hline
\end{tabular}


The questionnaire's reliability coefficient was calculated using Cronbach's alpha and it was obtained to be 0.766 . Since this coefficient was higher than 0.65 , the reliability of the questionnaire was approved. To ensure the questionnaire's validity, the experts of in-service training courses were first surveyed, and the questionnaire was designed based on their comments and views. Then, the questionnaire's validity was confirmed by factor analysis. Given that the factor load of no index was 0.4 , none of the questionnaire's indices were eliminated or amended.

\section{Data Analysis}

After the questionnaires were distributed, Kolmogorov-Smirnov test was performed using SPSS software to determine the samples' normality or abnormality, and the verification of the normality of the data, one-sided Student T-test was developed to test the formulated hypotheses consistent with the research questions. As the questionnaire was designed based on 7-item Likert scale, the mean was considered to be 4 .

Hypothesis 1: the individual factors have a significant impact on the effectiveness of in-service training courses among the English language teachers of the secondary schools. To examine this hypothesis, the following statistical hypothesis was presented.

The individual factors have not a significant impact on the effectiveness of in-service training courses among the English language teachers of the secondary schools. $H_{\circ}: \mu \leq 4$

The individual factors have a significant impact on the effectiveness of in-service training courses among the

English language teachers of the secondary schools. $H_{1}: \mu>4$

The results for one-sided Student T-test are presented in Table 2.

Table 2. The results from hypothesis 1

\begin{tabular}{|c|c|c|c|c|c|c|}
\hline \multicolumn{7}{|c|}{ Single-sample statistics } \\
\hline & \multicolumn{6}{|c|}{ Test Value $=4$} \\
\hline & \multirow[b]{2}{*}{$\mathrm{t}$} & \multirow[b]{2}{*}{ df } & \multirow[b]{2}{*}{ Sig. (2-tailed) } & \multirow[b]{2}{*}{ Mean Difference } & \multicolumn{2}{|c|}{$95 \%$ Confidence Interval of the Difference } \\
\hline & & & & & Lower & Upper \\
\hline Individual Factors & -6.219 & 101 & .000 & -.60924 & -.8036 & -.4149 \\
\hline
\end{tabular}

As shown in the above table, the null hypothesis is confirmed at the confidence level $95 \%$, and the opposite hypothesis is rejected, i.e., the individual factors have not a significant impact on the effectiveness of in-service training courses among the English language teachers of the secondary schools.

Hypothesis 2: the training factors have a significant impact on the effectiveness of in-service training courses among the English language teachers of the secondary schools. To examine this hypothesis, the following statistical hypothesis was presented.

The training factors have not a significant impact on the effectiveness of in-service training courses among the English language teachers of the secondary schools. $H$ : $\mu \leq 4$

The training factors have a significant impact on the effectiveness of in-service training courses among the English language teachers of the secondary schools. $H_{1}: \mu>4$

Table 3. The results from hypothesis 2

Single-sample statistics

\begin{tabular}{|c|c|c|c|c|c|c|}
\hline & \multicolumn{6}{|c|}{ Test Value $=4$} \\
\hline & \multirow[b]{2}{*}{$\mathrm{t}$} & \multirow[b]{2}{*}{ df } & \multirow[b]{2}{*}{ Sig. (2-tailed) } & \multirow[b]{2}{*}{ Mean Difference } & \multicolumn{2}{|c|}{$95 \%$ Confidence Interval of the Difference } \\
\hline & & & & & Lower & Upper \\
\hline Training factors & -7.341 & 101 & .000 & -.78431 & -.9962 & -.5724 \\
\hline
\end{tabular}


As shown in the above table, the null hypothesis is confirmed at the confidence level $95 \%$, and the opposite hypothesis is rejected, i.e. the training factors have not a significant impact on the effectiveness of in-service training courses among the English language teachers of the secondary schools.

However, as can be seen, the significance level at this dimension has a lower difference with 0.05 level, and this means that this dimension is received attention to some extent.

Hypothesis 3: organizational factors have a significant impact on the effectiveness of in-service training courses among the English language teachers of the secondary schools. To examine this hypothesis, the following statistical hypothesis was presented.

The organizational factors have not a significant impact on the effectiveness of in-service training courses among the English language teachers of the secondary schools. $H_{0}: \mu \leq 4$

The training factors have a significant impact on the effectiveness of in-service training courses among the English language teachers of the secondary schools. $H_{1}: \mu>4$

Table 4. The results from hypothesis 3

Single-sample statistics

\begin{tabular}{lllllll}
\hline & \multicolumn{1}{c}{ Test Value $=4$} \\
\cline { 2 - 6 } & $\mathrm{t}$ & $\mathrm{df}$ & Sig. (2-tailed) & Mean Difference & Lower & 95\% Confidence Interval of the Difference \\
$\begin{array}{l}\text { Organizational } \\
\text { FACTORS }\end{array}$ & 3.873 & 101 & .000 & .42484 & .2072 & .6425 \\
\hline
\end{tabular}

As shown in the above table, as the entire statistics are in a positive state, and the mean of the dimension is also greater than three other dimensions, we conclude that the organizational factors has a significant impact on the effectiveness of in-service training courses among the English language teachers of the secondary schools.

To respond the question that whether the effects of these three factors are the same or not, ANOVA was applied. The results indicated that, at the confidence level $95 \%$, there is a significance difference between the mean of the current situation of at least two of the three factors. To further clarify the results, and being informed of the presence of a significant difference between each of the categories, LSD and Tukey test were utilized in the research, and the results indicated that no difference can be observed among most of the categories, and there is only a significant difference between the third category (i.e., organizational factors) with other ones.

\subsection{Prioritization of the Indices Related To the Training Factors}

Given that the ANOVA results show the differences between the mean and the variance of the factors affecting the effectiveness of in-service training courses for English language teachers in terms of organizational factors, the significance of the indices was prioritized using TOPSIS technique only for the organizational factor. To perform TOPSIS technique, the same data relevant to the significant questionnaire was used, and actually a composite matrix of 14 variables and 102 responders were formed. The results from the indices' prioritization is presented as in the flowing table, and as can be observed, from the perspective of the study participants, the factors with the highest priority include "employment law tailored to attend educational courses", "organizational support of educational courses", "the score tailored to the participants in terms of promotion", and "organizational climate supportive of education". 
Table 5. The prioritization of the significance of the organizational factor on the effectiveness of in-service training courses

\begin{tabular}{|c|c|c|c|c|}
\hline Indicator & $\begin{array}{l}\text { Distance with } \\
\text { Positive Ideal }\end{array}$ & $\begin{array}{l}\text { Distance with } \\
\text { Negative Ideal }\end{array}$ & $\mathrm{Ci}$ & Rank \\
\hline Employment law tailored to attend educational courses & 0.011 & 0.025 & 0.689 & 1 \\
\hline Organizational support of educational courses & 0.016 & 0.027 & 0.630 & 2 \\
\hline $\begin{array}{l}\text { advantages and points proportionate to the participants in terms of promotion and } \\
\text { upgrade }\end{array}$ & 0.016 & 0.022 & 0.589 & 3 \\
\hline Organizational climate supportive of education & 0.020 & 0.025 & 0.552 & 4 \\
\hline Incentives rules to continue to participate in future courses & 0.024 & 0.025 & 0.510 & 5 \\
\hline $\begin{array}{l}\text { The existence of systematic structures for following-up and updating staff's } \\
\text { scientific capabilities }\end{array}$ & 0.022 & 0.023 & 0.505 & 6 \\
\hline $\begin{array}{l}\text { Allocate the leave with the least negative occupational consequences for } \\
\text { continuing education }\end{array}$ & 0.024 & 0.023 & 0.486 & 7 \\
\hline $\begin{array}{l}\text { The consistency between courses' content with job conditions during evaluation } \\
\text { session }\end{array}$ & 0.023 & 0.021 & 0.478 & 8 \\
\hline Continuous assessment to update the title and content of educational courses & 0.021 & 0.019 & 0.474 & 9 \\
\hline Financial support of the participants in the courses & 0.023 & 0.020 & 0.465 & 10 \\
\hline Institutional policy making in line with educational objectives & 0.025 & 0.020 & 0.444 & 11 \\
\hline Provide proper training assistance service to participants & 0.023 & 0.018 & 0.443 & 12 \\
\hline Job characteristics appropriate to the implementation of the training course & 0.01 & 0.007 & 0.399 & 13 \\
\hline Provide career counseling to participants & 0.01 & 0.007 & 0.399 & 14 \\
\hline
\end{tabular}

\section{Discussion and Conclusion}

In-service training is a highly efficient tool based on management's development-based approach, such that by utilizing it, training organizations can significantly achieve progress in the area of development and success. Given the necessity of progress and promotion of the teacher working under the supervision of the Department of Education, the current research seeks to assess and prioritize the factors affecting the effectiveness of in-service training courses from the perspective of English language teachers of the secondary schools in Tehran selected districts. The findings obtained from the hypotheses' test are indicative of the significant impact of individual and training factors on the effectiveness of teachers' training courses. This finding is consistent with that of the research performed by Abili et al. (2009), and Mahmoudi et al. (2012). On the other hand, the effectiveness of organizational factors on the effectiveness of in-service training courses is consistent with the finding obtained from the research performed by Herrero et al. (2011).

Based on the results from this prioritization of the indices related to organizational factors using TOPSIS, it was indicated that the factors with the highest priority include "employment law tailored to attend educational courses", "organizational support of educational courses", "score tailored to the participants in terms of promotion", and "organizational climate supportive of education":

Given that the most significant factor in training courses is organizational factor, and given the raking of the indicators in this dimension using TOPSIS, the following strategies were presented:

- Determine the evaluation criteria on the basis of occupational groups.

- Create an atmosphere of learning and creative support for continuous learning.

- Making school principals informed of the role that they should play in the area of evaluation.

- Design and implementation of a knowledge management system and comprehensive information management system on training programs for teachers.

- Promotion of teachers based on the points earned in training course rather than mere participation in the relevant course.

- Create a comprehensive system to convert people's knowledge into applied capabilities in the schools and promotion based on it.

- The possibility of promoting people based on their ability to do knowledge sharing, and train other teachers through their own knowledge.

- Establish financial and non-financial incentives for participation in job-related educational courses outside the organization. 
Finally, it is recommended, as organizational factor has a more significant impact (compared to two other factors) on the effectiveness of in-service training courses, it is of significance to upgrade organizational climate and managers' support, and also to convert training and education from a luxury need into one of the main activities of the organization.

On the other hand, based on the research results, and given that each research has its own limitations, and fail to cover all aspects of a problem, it is recommended to the researchers eager to perform research in this particular area to analyze and scrutinize some subjects including the effectiveness of the educational courses on labor productivity, the level of alignment between the organization's training strategy and a comprehensive strategy and the factors affecting it, evaluation of non-educational strategies for empowering managers and employees using quality function deployment model, the effectiveness of the educational courses on the explication of staff's knowledge and knowledge sharing, etc.

\section{References}

Abili, Kh., Sobhaninejad, M., \& Youzbashi, A. R. (2009). Factors affecting the promotion of the effectiveness of training courses (Case study: National Iranian Oil Company). Journal of management and human resources in the petroleum industry, 3(9), 59-76.

Bakhtiari, M., \& Ahmadi, Gh. R. (2007). The effectiveness of in-service training on information and communication technology (ICT) for the secondary school teachers in Isfahan, knowledge and research in educational Sciences. Khorasgan Islamic Azad University, 13, 123-134.

Chen, C., Sok, P., \& Sok, K. (2007). Exploring potential factors leading to effective training: An exclusive study on commercial banks in Cambodia. Journal of Management Development, 26(9), 843-856. http://dx.doi.org/10.1108/02621710710819339

Fathivajargah, K. (2010). Planning the in-service-training of the staff. Tehran: Samt Publication (In Persian).

Fouroghi, A. A. et al. (2008). Factors affecting the quality of in-service training on the employees in Khorasgan Islamic Azad University. Science and Research in Education, Curriculum, 19, 61-78.

Ghosh, P. et al. (2012). Towards more effective training programmers: a study of trainer attributes. Industrial and Commercial Training, 44(4), 194-202. http://dx.doi.org/10.1108/00197851211231469

Herrero, P. et al. (2011). Evaluation of training effectiveness in the Spanish health sector. Journal of Workplace Learning, 23(5), 315-330. http://dx.doi.org/10.1108/13665621111141911

Khorasani, A., \& Dousti, H. (2011). Assess the degree of satisfaction and the importance of factors affecting the effectiveness of electronic training from the perspective of employees (Case Study: Bank Saman). ICT in Educational Sciences, 1(4), 37-58.

Latif, K. F. (2012). An integrated model of training effectiveness and satisfaction with employee development interventions. Industrial and Commercial Training, 44(4), 211-222. http://dx.doi.org/10.1108/00197851211231487

Mahmoudi, M. T. et al. (2012). Evaluate the effectiveness of physicians' re-training courses from the perspective of the participants in these courses and Chahar Mahal province in 2012. Journal of Medical Sciences: Shahr-e-kord University, 14(4), 79-87.

Pour, J. Z. et al. (2011). The effectiveness of the training course of working with ECT to nurses based on Kirkpatrick's model. Iranian Journal of Medical Education, 8, 896-902.

Xu, Q., \& Jiang, J. (2010). The moderating role of cultural similarity in leadership training effectiveness. Journal of European Industrial Training, 34(3), 259-269. http://dx.doi.org/10.1108/03090591011031746

\section{Copyrights}

Copyright for this article is retained by the author(s), with first publication rights granted to the journal.

This is an open-access article distributed under the terms and conditions of the Creative Commons Attribution license (http://creativecommons.org/licenses/by/3.0/). 